\title{
PRÁTICAS INSTITUCIONAIS E INCLUSÃO ESCOLAR
}

\section{MARIA EUGÊNIA NABUCO}

Psicóloga clínica do Centro de Atendimento Psicológico para Crianças e Adolescentes de Claye-Souilly e do Setor de Psiquiatria de Seine-et-Marne - França

mariaeugenianabuco@noos.fr

\begin{abstract}
RESUMO
No Brasil a concepção de Educação Inclusiva é fortemente marcada pela noção de Educação Especial e pela categorização do comportamento dos alunos. O documento sobre a Política nacional de educação especial na perspectiva da educação inclusiva, entregue ao Ministro da Educação em 7 de janeiro de 2008, acentua as noções de transtorno global ou funcional, de deficiência e de déficit que acompanha este tipo de categorização. Vemos se desenhar nesse documento uma "psicopatologia da inclusão". Pela formulação de dois enunciados : "política é educação" e "educação é política", uma análise das contradições das políticas educativas e suas institucionalizações é apresentada a partir de um referencial teórico da psicánalise de orientação lacaniana.

EDUCAÇÃO ESPECIAL - PSICOLOGIA DO COMPORTAMENTO - PSICANÁLISE - EDUCAÇÃO INCLUSIVA
\end{abstract}

\section{ABSTRACT}

INSTITUTIONAL PRACTICES AND EDUCATIONAL INCLUSION. In Brazil the conception of inclusive education is strongly shaped by the notion of special education and the categorization of pupils' behaviour. A document called Special education national policy in the perspective of inclusive education was submitted to the Education Minister on January 7th 2008. It stresses the notions of global or functional disorders, deficiency and deficit which go with that kind of categorization. A tendency towards a "psychopathology of inclusion" is becoming apparent in this document. Using two expressions "policy is education" and "education is policy" we analyse the contradictions of education policies and their institutionnalizations from the theoretical frame of lacanian oriented psychoanalysis.

SPECIAL EDUCATION - BEHAVIORS PSYCHOLOGY - PSYCHOANALYSIS -INCLUSIVE EDUCATION

Conferência realizada no Seminário Internacional sobre Educação Inclusiva - Seminedi -, ocorrido em 24 a 26 de abril de 2008, na cidade de São Paulo, organizado pela professora doutora Maria Alice Rosmaninho Perez. Em francês deu origem ao texto "Pratiques institutionelles et inclusion scolaire dans la problematique brésilienne", publicado em La Nouvelle Revue de L'Adaptation et de la Scolarisation, Paris, série especial n.5, p.257-265, jul. 2009 (L'éducation inclusive en France et dans le monde). 


\section{EDUCAÇÃO ESPECIAL NA PERSPECTIVA DA EDUCAÇÃO INCLUSIVA: UMA PSICOPATOLOGIA DA INCLUSÃO}

As reflexões que se seguem sobre práticas institucionais e inclusão escolar estão intimamente ligadas à minha prática clínica. Uma prática psicanalítica que ela mesma, enquanto prática, não deixa de suscitar interrogações. Essas reflexões são marcadas por uma série de ferramentas conceituais que Sigmund Freud e Jacques Lacan nos legaram e que quando aplicadas nos esclarecem e orientam sobre os debates da civilização que testemunhamos.

Não somente o mal-estar na cultura se agrava, mas as respostas que a sociedade fabrica mudam de natureza e de forma. Eu diria que não é somente no domínio tradicional da arte e da cultura que encontramos os signos desse novo "mal-estar", mas também nas soluções dadas a ele. Constatamos cada vez mais essas respostas no discurso da ciência, inclusive nas novidades resultantes de seu progresso, como por exemplo a gritante expansão da psicofarmacologia, como também nas técnicas de controle do comportamento e de gestão do social. As terapias cognitivas comportamentais são aqui um verdadeiro paradigma das formas de condicionamento social (Laurent, 2008).

Entre os novos sintomas contemporâneos e as falsas respostas que aprisionam o sujeito em uma ilusão de "bem-estar", e considerando ainda aquelas que não respondem as equações dos problemas para os quais se tenta encontrar uma solução, custe o que custar, eu proponho para o nosso debate uma mudança no tema central deste encontro, formulando a seguinte proposição: curar-se da Educação Especial e da "psicopatologia da inclusão".

A hipótese de trabalho que formulo para o debate desta problemática é a de que a sociedade que se desenvolve do século XVIII até o período contemporâneo não recusou ao indivíduo o reconhecimento de sua "peculiaridade" '. Ao contrário, pôs em prática toda uma aparelhagem institucional que produz discursos sobre ela. Daí a fabricação do que nomeio "psicopatologia da inclusão"?

I. Insisto aqui sobre o uso da palavra "peculiaridade" e não "singularidade", uma vez que a educação dificilmente se ocupa ou se ocupou do que é particular, singular ao sujeito.

2. O termo me ocorreu em fevereiro de 2008 , durante a leitura do documento elaborado pelo grupo de trabalho nomeado pelas portarias n.555 e 948/2007 e entregue ao Ministro da Educação em 7 de janeiro de 2008. Apresento, assim, no 2 Seminedi, as primeiras formulações em torno dessa noção. 
Um dos exemplos entre muitos que podemos isolar para o nosso debate em torno desse conceito de psicopatologia da inclusão, e que se traduz por uma categorização de comportamentos observáveis e pela noção de transtorno global e ou funcional, deficiência e déficit que os acompanha, pode ser encontrado no texto Política nacional de educação especial na perspectiva da educação inclusiva.

Esse documento certamente foi produzido em função de diferentes grupos de pressão, tais como as associações que gerem estabelecimentos especiais e que revendicam e lutam pela sua manutenção, como as associações Pestalozzi e as dos Pais e Amigos dos Excepcionais - Apaes. Pela sua riqueza e objetividade, o texto nos permite formular questões que tocam diretamente a problemática da inclusão, presa ainda nas armadilhas da Educação Especial. Na realidade o Brasil é um dos raros países que continua a utilizar a expressão Educação Especial.

Nesse documento de proposições, dados relevantes históricos e teóricos são apresentados e, no item 5, intitulado "Alunos atendidos pela educação especial", encontramos a seguinte menção: "Na perspectiva da educação inclusiva, a educação especial passa a constituir a proposta pedagógica da escola, definindo como seu público-alvo os alunos com deficiência, transtornos globais de desenvolvimento e altas habilidades/superdotação". Ao caracterizar esse público-alvo, o documento a ele se refere:

Consideram-se alunos com deficiência àqueles que têm impedimentos de longo prazo, de natureza física, mental, intelectual ou sensorial, que em interação com diversas barreiras podem ter restringida sua participação plena e efetiva na escola e na sociedade. Os alunos com transtornos globais do desenvolvimento são aqueles que apresentam alterações qualitativas das interações sociais recíprocas e na comunicação, um repertório de interesses e atividades restrito, estereotipado e repetitivo. Incluem-se nesse grupo alunos com autismo, síndromes do espectro do autismo e psicose infantil. Alunos com altas habilidades/superdotação demonstram potencial elevado em qualquer uma das seguintes áreas, isoladas ou combinadas: intelectual, acadêmica, liderança, psicomotricidade e artes. Também apresentam elevada criatividade, grande envolvimento na aprendizagem e realização de tarefas em áreas de seu interesse. Dentre os transtornos funcionais específicos estão: dislexia, disortografia, disgrafia, discalculia, transtorno de atenção e hiperatividade, entre outros. 
No item 6, "Diretrizes da política nacional de educação especial na perspectiva da educação inclusiva", temos:

A Educação Especial é uma modalidade de ensino que perpassa todos os níveis, etapas e modalidades, realiza o atendimento educacional especializado, disponibiliza os serviços e recursos próprios desse atendimento e orienta os alunos e seus professores quanto a sua utilização nas turmas comuns do ensino regular. No mesmo item VI há ainda: A interface da Educação Especial na educação indígena, do campo e quilombola deve assegurar que os recursos, serviços e atendimento educacional especializado estejam presentes nos projetos construídos com base nas diferenças socioculturais desses grupos.

No item 7, "Referências bibliográficas", encontramos textos oficiais: do Ministério da Educação e da Secretaria de Educação Especial ( 989 , 1994, 1999, 2000, 200 I, 2002, 2004, 2006), as Leis de Diretrizes e Bases da Educação Nacional (1961, 1971, 1996), o Estatuto da Criança e do Adolescente (1990), o Plano de Desenvolvimento da Educação (2007); o Censo Demográfico (2000); o Censo Escolar (2006); o Decreto sobre a Convenção Interamericana para a Eliminação de Todas as Formas de Discriminação contra Pessoas Portadoras de Deficiência (Guatemala, 200 I); a Declaração Mundial sobre a Educação para Todos (Unesco, Jomtiem/Tailândia, 1990), Declaração de Salamanca (1994); a Convenção da ONU sobre os direitos das pessoas com deficiência (2006).

Estudando o documento de modo sistemático, pude formular uma série de questões:

I. Será possível conceber a educação como inclusiva a partir de uma política nacional de Educação Especial?

2. A Educação Especial em si já não seria uma fabricação da categoria de desviantes estigmatizados em noções pseudocientíficas de déficit ou de superdotação?

a. Grupos de culturas representados pelos indígenas, homens do campo e quilombolas seriam categorias suplementares em interface com a Educação Especial? Uma justaposição de categorias culturais e noções de deficiência? 
b. Uma política nacional de Educação Especial teria por função definir o seu público-alvo, em "categorias de crianças", fundamentandose em orientação teórica única que se impõe como resposta verossímil?

c. Teria essa política por função tomar partido de uma orientação teórica específica e, por meio dela, impor um modelo social?

d. Acatando esta opção, não estaríamos assistindo ao nascimento de uma "psicopatologia de Estado da inclusão"?

3. Sendo a Educação Especial uma política nacional e uma proposta pedagógica da escola na perspectiva da Educação Inclusiva, o risco não seria o de incluí-la em uma tradição histórica de exclusão?

a .Como manejar, na construção da prática de inclusão, a ambiguidade que oscila entre política nacional e proposta pedagógica?

b. Caberia à Educação Especial realizar, orientar e administrar o "atendimento educacional especializado"?

A Educação Especial repousa sobre contradições sociais de categorias, por exemplo sobre noções de deficiência e de inadaptação e também sobre instituições e públicos específicos. A educação inclusiva implica a igualdade de oportunidades para todos e o acesso a um direito universal. $O$ atendimento especializado é destinado e sobretudo põe em evidência a singularidade do sujeito. Essas diferentes orientações não são construídas a partir de paradigmas opostos, de categorias conceituais distintas cujos efeitos objetivos definem uma pluralidade de instituições e práticas? Tais contradições encontradas no Brasil estão presentes em outros países como a Itália, a Inglaterra e a França, a despeito das suas histórias particulares.

Nós nos propomos agora a contribuir para a análise das contradições das políticas educativas e das suas institucionalizações, desenvolvendo dois enunciados: política é educação; educação é política.

\section{POLÍTICA É EDUCAÇÃO}

O enunciado "educação é política" não é simplesmente um equivalente do enunciado "política é educação". Freud, segundo uma anedota célebre, respondia: "Politicamente, eu não sou nada" (Eastmann, apud Reich, 1972, p.62), 
ao ser questionado sobre uma possível adesão partidária. Poderíamos tomar essa negação por um banal "apoliticismo", mas, longe de uma neutralidade descolorida, Freud decifrava a política dentro do cenário de crise revelado pela Primeira Guerra Mundial (Freud, 1915, 1932). Ele demonstra claramente os ideais que abriram as vias ao fenômeno do totalitarismo e, em se tratando de ordem política, nada mais nocivo que uma conversa em torno de ideal.

Freud revela a morbidade do ideal no estudo do caso do presidente americano Thomas Woodrow Wilson ${ }^{3}$, em que o que é posto em evidência são os conflitos psíquicos de um homem político e a contribuição destes para a construção da história. A relação entre a política e o inconsciente não é assim neutra no sentido dado por Freud e, sem jamais tratar diretamente de política, ele evidencia que a própria política suscita o inconsciente. Nada pior então, para Freud, que um "idealista passional" no poder. Lacan, retomando Freud, o considera um humanista em face da política e não um indiferente indiferente premeditado.

Citando Jacques-Alain Miller (2002), Freud explicitaria a tese "a política é o inconsciente", no texto Psicologia das massas e análise do eu (I921), em que analisa as formações coletivas como formações do inconsciente, que têm um mesmo "significante de identificação" e "uma mesma causa de desejo". A instituição é considerada aqui por Freud como "massa", uma multidão indiferenciada, sendo o Exército e a Igreja dois modelos exemplares desse tipo de estrutura. Os princípios que as edificam são a "identificação" e o "amor". No

3. A ideia de um estudo do presidente americano Thomas Woodrow Wilson, falecido em 3 de fevereiro de 1924, ocorre a Freud em 1929. Doente e deprimido nessa data, Freud recebe em Berlin a visita do diplomata americano William Bullitt, que the apresenta um projeto de estudo sobre os chefes de Estado que participaram da redação do Tratado de Versailles, e que foram considerados diretamente responsáveis pela eclosão da Segunda Guerra Mundial. Freud, na introdução do seu estudo, conclui: "Os loucos, os visionários, os alucinados, os neuróticos e os doentes mentais, em todos os tempos, ocuparam lugares importantes na história da humanidade. [...] São precisamente os traços patológicos do seu caráter, a assimetria do seu desenvolvimento, o reforço anormal de certos desejos, o abandono sem reserva e nem discernimento a um objetivo único, que lhes dão a força de envolver os outros e de vencer a resistência do mundo. [...] As grandes obras coincidem tanto com as anomalias psíquicas, que somos tentados a acreditar que elas são inseparáveis. [...] A identificação com o pai e posteriormente com o chefe, e enfim com Deus, nos revela o quanto essas mesmas identificações influenciaram sua vida como chefe de Estado e, consequentemente, suas decisões políticas". 
Exército, a identificação transversal de cada soldado com seu semelhante e o amor ao chefe e, na Igreja, a identificação do sujeito com seus irmãos e o amor a Cristo. Nesse caso, temos um duplo laço libidinal pela identificação de cada religioso com Cristo. Segundo Freud, uma relativa inversão do objeto de amor e do objeto de identificação ocorreria aqui: a identificação com Cristo permite o amor ao próximo. Identificação e amor são assim duas modalidades de laço social entre semelhantes e essa é uma das vias pela qual a psicanálise aborda a problemática das instituições. $\bigcirc$ estudo da Psicologia coletiva revela como um grupo pode perpetuar-se por meio da identificação com um ideal comum, o que para nos é fundamental para a discussão sobre Educação Especial e Educação Inclusiva.

Os textos "Mal-estar na civilização", de 1930, e "Moisés e o monoteísmo”, de 1939, podem ser lidos à luz desta mesma tese (Miller, 2002). Freud, embora não fale de política, não deixa de buscar no seu campo os exemplos necessários à formulação de suas teses. É nesse campo que ele organiza seus estudos sobre identificação, censura, repressão e mesmo repressão do desejo.

O enunciado "política é educação" evocaria portanto a tese freudiana na qual a política suscita o inconsciente. Os debates em torno da Educação Especial e da Educação Inclusiva fazem parte de uma psicopatologia contemporânea, isto é, de um social subjetivo, implicando julgamentos de valores e gestão de comportamentos. Um discurso que revela os ideais de um determinado tipo de sociedade, ou seja, o que a sociedade espera de seus membros. A ressonância explícita desse discurso pode ser encontrada no pressuposto do aluno ideal e do professor idealizado, que tomados como objetos de satisfação de uma sociedade ideal, responderiam, nas situações de ensino-aprendizagem, conforme o modelo freudiano da massi cação. A educação ideal, a escola ideal, com seus alunos e professores ideais, seriam aqui fontes de modelos de identi cação. Esse mesmo discurso revela ainda os ideais das famílias, dos professores e pesquisadores envolvidos na formação pro ssional dos especialistas da área da saúde e outras a ns, das associações, dos políticos e governantes comprometidos com a questão. Revela também os bastidores do poder e seus trâmites.

Na realidade, por ser o processo político uma constante entre construção/desconstrução e representar a realização de um ideal educativo, o seu discurso visaria decididamente atrair as massas, o que exige versatilidade 
discursiva e arranjos dos governantes e de seus pares. $O$ Estado, ao legislar sobre uma política nacional de Educação Especial na perspectiva da Educação Inclusiva, assume o seu lugar simbólico de regulação de diferenças insuperáveis entre os sujeitos. A armadilha nesse processo de regulação é visar à categorização arbitrária do que é singular, particular e subjetivo de cada ser humano, tenha ele de forma mais acentuada ou não "necessidades educativas especiais". Como construção arbitrária de categorias podemos citar a tentativa de regulação de comportamentos em torno da dislexia, disortografia, disgrafia, discalculia, transtorno de atenção e hiperatividade, da superdotação, entre outros. Ou ainda das crianças psicóticas, autistas e neuróticas graves, tidas como deficientes em determinadas teorias.

A palavra "deficiência" tem origem no latim - deficientia -, o que aponta para a falta, a imperfeição e a insuficiência. Como construir uma prática escolar edificada sobre esse tipo de discurso ou sobre o seu contrário?

A forma pela qual essas diferenças serão reguladas simbolicamente ou imaginariamente na construção/desconstrução de políticas de Educação Especial e de práticas de inclusão é que determinará o estilo de governança da subjetividade humana. O antropólogo Maurice Godelier (2007) estabelece uma relação entre "violência e consentimento na gênese e na perpetuação de relações de dominação e exploração", características das sociedades em que reina a desigualdade social. Entre reprodução social e violência simbólica, a escola, os professores e as famílias não têm escapado a essa fabricação do arbitrário. Como afirma o sociólogo Michel Chauvière (2006), o excesso atual de gestão líquida, o que a própria política poderia recriar e inovar no social. "Política é educação" será, na lógica desse discurso, um enunciado pouco modesto e reducionista e eu o diferenciaria do enunciado: "educação é política".

\section{EDUCAÇÃO É POLÍTICA}

A educação como processo de socialização (Durkheim, 1922) não deixa de ser e de visar à transmissão do laço social. Tudo o que é "novo" suscita um processo de socialização, e a criação como processo social é ela também laço social. A novidade, sendo uma ligação necessária com o Outro, infere uma relação social subjetiva na perspectiva psicanalítica (Laurent, Miller, 1996/1997). 
Implica a dimensão de um inconsciente transindividual que está na base do fundamento do laço social. Podemos nos colocar então as seguintes questões: que tipo de laço social desejamos construir; que valor tentaremos dar à subjetividade em nossa prática? Essas questões nos remetem à noção de instituição e a sua utilidade social (Arendt, 1954). Instituições particulares são necessárias para darmos lugar à subjetividade e à singularidade do Sujeito.

A palavra "instituição", do latim institutio, designa uma estrutura de organização de origem humana, destinada a inscrever-se no tempo. O termo tem, assim, um duplo percurso semântico que se estabelece entre regra e comunidade de vida. Para Lacan, enquanto "formação humana", toda instituição tem por essência frear a "pulsão de morte", o gozo, e instaurar o laço social pela via do discurso. Instituições e práticas são discursos que produzem e fazem existir o laço social. As instituições escolares não escapam a essa definição. Todos os grupos humanos - família, escola, associações, entre outros - têm um papel primordial na transmissão da cultura e eles estabelecem entre as gerações uma "continuidade psíquica onde a causalidade é de ordem mental" (Lacan, 1966).

Disposições psíquicas fazem existir e durar o laço social, e é com essas disposições que os professores se confrontam nas situações escolares. Dificuldades de aprendizagem respondem a essas condições, e é nesse sentido que vemos, com frequência, os professores dizerem "eu não estou preparado para isso". Mas o que significa estar preparado? A questão não é simples, pois a afirmação vem com frequência acompanhada de uma dor íntima, subjetiva. Teria de ser considerado o que é feito aqui da subjetividade do professor. Que resposta política e qual formação profissional propor?

A educação como política põe em evidência o "Outro que não existe" (Laurent, Miller, 1996/1997), e essa relação com o Outro é intrínseca na educação. Esse Outro inexistente faz parte do processo social. Lacan articula o sujeito do inconsciente a um Outro e o quali ca como transindividual. Segundo Miller (2002), nós podemos passar do "inconsciente transindividual" ao "inconsciente político", e nessa passagem saímos do reducionismo da "política é o inconsciente" para colocálo na era da globalização, da pós-modernidade. Na era do "efêmero, da celebridade derrisória, da vida líquida”, como a rma Bauman (2000a, 2006). O que não deixa de ser um desa o para a educação. A mundialização da condição humana que começa a se desenhar de nindo novas orientações e estratégias políticas "volatizou 
os limites e produziu uma massa de excluídos" (Bauman, 2003), os liquidados, "aqueles que são desnecessários" (Bauman, 2000, 2002, 2003a, 2004, 2006), e que não fazem parte da edificação do social e de suas instituições.

As práticas de inclusão e a educação estão às voltas com essa modernidade líquida e com o fluxo da informação sem fronteiras que aparece como desestruturação e esgarçamento dos laços sociais, o que não deixa de acelerar o processo de segregação/exclusão.

A metáfora do "líquido", de Zygmunt Bauman, acaba de entrar na psicanálise de orientação lacaniana pelas elaborações recentes de Jacques-Alain Miller. Introduzir essa metáfora é adotar, no que concerne à experiência analítica, "a imagem do fluido, do que não é sólido, do que escorre, do que escapa como inatingível" (Miller, 2007/2008). Nas práticas institucionais, em se tratando da particularidade do sujeito, a metáfora evoca o que é transformável, móvel, brando, o que desliza e pode passar ao largo como resposta a ser construída e inventada.

Para a educação que se constrói no espaço social, a metáfora do líquido, da sociedade líquida, abre outros espaços e concepções sobre os seres humanos, principalmente para aqueles que são visados como populações a serem incluídas pelo processo educativo. As categorizações reducionistas, as de ciências pressupostas, as disfunções neurológicas atribuídas às alterações do corpo e da linguagem, podem-se bene ciar dessa liquidi cação das fronteiras entre o normal e o patológico. Esses seres humanos são portadores de sintomas que têm um sentido nas suas existências e que não podem ser reduzidos a pressupostos construídos a priori, mesmo que esses ditos dé cits perturbem o curso considerado normal de suas aprendizagens.

A famosa frase de Lacan, que provoca ironia e riso - "não existe relação [rapport] sexual" -, inscreve-se nesse quadro do desaparecimento da norma, da universalização. Não existe norma que possa regular o que é da pulsão. O que existe é satisfação pulsional e a pulsão não tem disciplina, tem gozo. Aqui saímos da era da educação repressiva e entramos na era da invenção e da criação fora da norma, fora da complementaridade. Respondendo a essa fluidificação e gozo da era da globalização é que as práticas podem ser reinventadas e as instituições podem ganhar em utilidade social. $\bigcirc$ que fica para todos como referência e princípio fora da norma é a ética. Por esse caminho podemos fazer circular um discurso que humanize e produza laços sociais. Este é o grande desafio para a educação. 


\section{REFERÊNCIAS BIBLIOGRÁFICAS}

ARENDT, H. La Crise de la culture. Paris: Folio, 1954.

BAUMAN, Z. L'Amour liquide: de la fragilité des liens entre les hommes. Rodez: Rouergue/ Chambon, 2004.

La Conférence de l'université de tous les savoirs, 18 juillet 2003. Disponível em: http://www.lemonde.fr/savoirs-et-connaissances/article/2003/06/25/zygmunt-baumanvivre-et-parfois-mourir-dans-un-monde-plein_325340_3328.html. Acesso em: mar.2008.

Le Coût humain de la mondialistion. Paris: Hachette, 2000.

Guerre de reconnaissance sur la frontière planétaire. Sprit, Paris, n. 12 ,

p.59-70, 2002.

Liquid modernity. 2000a. Disponível em: www.polity.co.uk/book. asp?ref $=074562409 \times$. Acesso em: mar. 2008.

La Vie liquide. Rodez: Rouergue/Chambon, 2006.

La Vie en miettes. Rodez: Rouergue/Chambon, 2003a.

CHAUVIÈRE, M. Trop de gestion tue le social: essai sur une discrète chanlandisation. Paris: Dunod, 2006.

DURKHEIM, E. Éducation et societé. Paris: Alcan, 1922.

FREUD, S. Considérations sur la guerre. 1915. Disponível em: http//www.classiques.uqac. ca/.../freud...considerations/Freud_considerations.pdf. Acesso em: mar. 2009.

Porquoi la guerre? Paris: PUF, 1932.

Psychologie des masses et analyse du moi. Paris: PUF, I921.

GODELIER, M. Au fondement des sociétés humaines: ce que nous apprend l'antropologie. Paris: Albin Michel, 2007.

LACAN, J. Propos sur la causalité psychique. Écrit. Paris: Seuil, 1966. p. I51-192.

LAURENT, E. Lost in cognition: psychanalyse et sciences cognitives. Paris: Cécile Defaut, 2008.

LAURENT, É.; MILLER, J.-A. L'Autre qui n'existe pas et ses comités d'éthique (I 996-1997). In: SEMINAIRE TENU DANS LE CADRE DE LA SECTION CLINIQUE. Paris: Département De Psychanalyse de L'université de Paris 8. mimeo. 
MILLER, J.-A. Instuitions milaneses, I. Mental, Paris, n. I I, p.9-2I, déc. 2002. (La clinique analytique à l'époque de la globalisation)

La Psychanalyse liquide. In: SÉMINAIRE 2007/2008. Section clinique. Cours du 12 march 2008. Paris.

REICH, W. Reich parle de Freud. Paris: Payot, 1972.

Recebido em: janeiro 2010

Aprovado para publicação em: janeiro 2010 